\title{
Rekonstruksi Metafisika Seyyed Hossein Nasr dan Pendidikan Spiritual
}

\author{
Azaki Khoirudin \\ Pascasarjana UIN Sunan Kalijaga. Jl. Laksda Adi Sucipto, \\ Yogyakarta, dan Pimpinan Pusat Ikatan Pelajar Muhammadiyah \\ 2014-2016.Email:zakielfikry@ipm.or.id
}

\begin{abstract}
This article examines Seyyed Hossein Nasr's thought on metaphysics and its relation to spiritual education. Nasr's paradigm is based on the universality and absolute dimension of Islam. Nasr utilizes Islamic intellectual tradition such as kalam, philosophy and mysticism as a tool to explain Islamic teachings. As a disciple of Shuhrawardi's philosophy of illumination, Nasr proposes a concept called scientia sacra as an authentic knowledge because it is derived from the Quran and human intellect. Scientia sacra appears in the form of "al-'ilm al-hudluri". As regard crises faced by modern human beings, the forgotten tradition derived from Islamic sufism should be included in the current Islamic education model as an answer to the thirst for spirituality among modern humankinds.

Keywords: metaphysics, scientia sacra, spiritual education, Seyyed Hossein Nasr
\end{abstract}

\section{ABSTRAK}

Astikel ini membahas paradigma spiritualitas Nasr tentang metafisika dan kaitannya dengan pendidikan spiritual. Paradigma Nasr didasari universalitas dan absolutiditas Islam. Dia menggunakan tradisi pemikiran Islam seperti kalam, filsafat dan tasawuf sebagai alat bantu dalam menderivasikan ajaran Islam. Sebagai pewaris filasafat iluminasi Suhrawardi, Nasr menawarkan suatu konsep tentang scientia sacra sebagai pengetahuan yang sejati karena bersumber pada wahyu dan inteleksi manusia. Scientia sacra bisa berwujud dalam bentuk "al-'ilm al-hudluri". Berkenaan dengan krisis kemanusiaan yang dialami manusia modern, Nasr menawarkan solusi agar pendidikan Islam kembali kepada tradisi Islam yang didalamnya terkandung ajaran sufisme sebagai yang paling bisa memberikan jawaban memuaskan atas kehausan spiritual manusia modern.

Kata Kunci: metafisika, scientia sacra, pendidikan spiritual, Seyyed Hossein Nasr

\section{PENDAHULUAN}

Dewasa ini, dunia modern dilanda berbagai krisis yang kompleks. Baik itu krisis alam, krisis kebudayaanperadaban, krisis sosial-ekonomi, krisis pendidikan dan krisis-krisis lainnya yang antara satu dengan lainnya hampir memiliki hubungan. Banyak orang mulai jenuh dengan kehidupan dunia ini. Mereka menginginkan keadilan, kesejahteraan, keamanan, dan perdamaian. Namun kenyataanya mereka semakin terpuruk, di Eropa saat ini pengangguran meningkat dari tahun sebelumnya.

Ada banyak idiom yang digunakan orang untuk menandai kehidupan masyarakat modern dewasa ini, 
misalnya, "hilangnya pesona dunia" (Max Weber), "terputusnya rantai kemajuan material dan kemajuan moral” (Bertrand Russel), "kesenjangan hati dan fikiran"

(Rabindranath Tagore), "sindroma keterasingan" (Fromm), "kekosongan rohani" (Leahy), ataupun the age of anxiety (Bastaman), adapun Hossein Nasr memiliki idiom “nestapa manusia modern". Idiom-idiom semacam itu menunjukkan adanya krisis yang diderita manusia yang hidup di zaman ini. Multikrisis yang disinyalir bersumber pada kekosongan jiwa manusia modern akan "makna", baik dalam arti ideologis, moral, mitologis maupun spiritual

Modernisme akhirnya dirasakan membawa kehampaan dan ketidak bermaknaan hidup. Timbul berbagai kritik dan usaha pencarian baru. Manusia membutuhkan pola pemikiran baru yang diharapkan membawa kesadaran dan pola kehidupan baru. Dalam hal kesadaran manusia, secara praktis, timbul gejala pencarian makna hidup dan upaya penemuan diri pada kepercayaan-kepercayaan yang sarat dengan spiritualitas. Di sinilah letak urgensi menggali pemikiran Hossein Nasr tentang konsep rekonstruksi metafisika dalam pembangunan spiritualitas yang hilang. Sehingga, artikel ini membahas rekonstruksi metafisika Nasr dan relevansinya dengan pendidikan spiritualitas.

\section{BIOGRAFI SEYYED HOSSEIN NASR}

Seyyed Hossein Nasr lahir pada tanggal 7 April 1933, di kota Teheran, Iran, negara tempat lahirnya para sufi, filosofi, ilmuwan dan penyair muslim terkemuka. Ayahnya, Seyyed Valiullah Nasr, di samping terkenal sebagai seorang ulama di Iran pada masanya, juga dikenal sebagai seorang dokter dan pendidik pada masa berkuasanya Reza Shah, ia diangkat setingkat dengan jabatan Menteri Pendidikan (untuk masa sekarang). ${ }^{1}$

Pendidikan dasarnya diperoleh secara informal dari keluarga dan secara formal pendidikan tradisional di Teheran. Di lembaga ini, ia mendapatkan pelajaran menghafal al-Quran dan menghafal syair-syair Persia klasik. Pelajaran ini sangat membekas dalam jiwa dan pikiran Nasr. Kemudian ayahnya mengirim belajar kepada sejumlah ulama besar di Qum Iran, termasuk kepada Thabathaba'i, penulis tafsir Mizan, untuk mendalami filsafat, ilmu kalam dan tasawuf. ${ }^{2}$

Pendidikan tingginya ditempuh di Amerika di Massachusetts Institute of Technologi (MIT), dimana ia berhasil mendapatkan diploma B.S. (Bachelor of Science) dan M.A. (Master of Art) dalam bidang fisika. Prestasi yang disandangnya belum memuaskan dirinya. Ia melanjutkan ke Universitas Harvard menekuni History of Science and Philosophy, dimana ia Nasr berhasil memperoleh gelar Ph.D (Doctor of Philosophy) pada tahun $1958 .^{3}$

Memandang kritikannya terhadap modernisme dan tokoh-tokoh modernis sekaligus mempertimbangkan warna pemikirannya, Nasr sangat boleh jadi merupakan pemikir aliran pasca-modernis. Pasca-modernisme Nasr, seperti tercermin dalam pemikirannya, mengambil bentuk kembali kepada Islam "tradisional”. Dalam kerangka ini, orang tradisonal adalah ia yang ingin memegangi "tradisi" yang suci, abadi, mempunyai kebijaksanaan yang perenial. Lebih dari itu, Nasr sangat mungkin pula adalah seorang "neo-sufi", yang menerima pluralisme dan perennialisme dalam kehidupan keagamaan. Neo-Sufisme Nasr adalah tasawuf yang menekankan aktivisme; 
tasawuf yang tidak mengakibatkan pengamalnya mengundurkan diri dari kehidupan dunia, tetapi sebaliknya melakukan inner detachment untuk mencapai realisasi spiritual yang lebih maksimal. ${ }^{4}$

\section{KIPRAH SEYYED HOSSEIN NASR DALAM PEMIKIRAN ISLAM}

Setelah memperoleh gelar Ph.D. dalam bidang sejarah sains dan filsafat Islam dari Harvard University, pada tahun 1958, Nasr kembali ke Iran. Di sini ia lebih mendalami filsafat Timur dan filsafat tradisional dengan banyak diskusi bersama para tokoh terkemuka agama Iran, seperti Thabathaba'i, Abu Hasan al-Qazwini, dan Kazin Asar.

Dalam kegiatan akademik, Nasr mengajar di Universitas Teheran, menjadi dekan fakultas sastra pada lembaga yang sama tahun 19681972, ${ }^{5}$ dan pada tahun 1962-1965 ia diangkat sebagai profesor tamu pada Harvard University. Ia juga sarjana yang menduduki pimpinan Aga Khan Chair of Islamic Studies yang baru dibentuk di American University of Beirut (1964-1965). Pada tahun 1975- 1979 Nasr menjadi direktur Imperial Iranian Academy of Philosophy, sebuah lembaga yang didirikan dinasti Syah Reza Pahlevi, untuk memajukan pendidikan dan kajian filsafat. Nasr berhasil dalam tugas ini sehingga ia diberi gelar kebangsaan oleh Syah.

Kredibilitas Nasr sebagai intelektual dan akademisi tidak hanya dikenal di negaranya sendiri tetapi juga diakui di negeri lain, sehingga sering diundang seminar atau memberi kuliah di luar negeri. Antara lain, memberi kuliah tamu di Harvard, Amerika, tahun 1962-1965, Universitas Amerika di Beirut, tahun 1964-1965, menjadi direktur lembaga Aga Khan untuk kajian ke-Islaman (Aga Khan Chair Of Islamic Studies) pada
Universitas yang sama. Nasr juga memberikan makalah pada Pakistan Philosophical Congress, di Pakistan, tahun 1964; memberikan kuliah di Universitas Chicago, tahun 1966, atas sponsor Rockefeller Foundation, dan tahun 1981 memberi kuliah di Giffort Lectures, lembaga yang didirikan oleh Universitas Edinburg tahun $1989{ }^{6}$

Nasr pernah datang juga ke Indonesia, Juni 1993 atas undangan Yayasan Wakaf Paramadina bekerja sama dengan penerbit Mizan. Di sini ia memberi tiga ceramah dengan topik berbeda, (1) tentang 'Seni Islam' sekaligus peluncuran buku Spiritualitas dan Seni Islam (Bandung, Mizan, 1993), (2) tentang 'Spritualitas, krisis dunia modern dan agama masa depan', (3) tentang 'filsafat perenial'. ${ }^{7}$ Adapun Karya-karyanya diantaranya adalah ${ }^{8}$ : Three Muslim Sages (1962); An Introduction to Islamic Cosmological Doctrine: Conceptions of Nature and Methods Used for Its Study by the Ikhwan ash-Shafa, alBiruni and Ibn Sina (1964); Islamic Science An Illustrated Study (1964); Ideals and Realitties of Islam (1965), terjemahan bahasa Indonesia berjudul Islam dalam Cita dan Fakta; Science and Civilization in Islam ( 1968); Man and Nature: the Spiritual Crisis of Modern Man. (1968); Sufi Essays (1972); Islam and The Plight of Modern Man (1975), terjemahan bahasa Indonesia berjudul Islam dan Nestapa Manusia Modern; Knowledge and the Sacred (1981), terjemahan bahasa Indonesia berjudul Inteligensi dan Spiritualitas Agama-Agama; The Encounter Man and Nature (1984), terjemahan bahasa Indonesia berjudul Antara Tuhan, Manusia dan Alam; Traditional Islam in the Modern World (1987); Islamic Art and Spirituality (1987).; The Need for Sacred Science (1993); Religion and The Order of Nature (1994); The Heart of Islam: Enduring Values for Humanity 
(2002), terjemahan bahasa Indonesia berjudul The Heart of Islam: Pesan-Pesan Universal Islam untuk Kemanusiaan.

\section{The New Metaphysics}

Sejak awal, Syeed Hossein Nasr, titik tolak pemikirannya didasari atas konsep dua hal: Pertama, adalah kritiknya terhadap modernitas, Kedua, karena fokus awalnya keilmuannya adalah "fisika" maka Nasr sangat mencintai "nature (alam)". Keduanya, baik kritik modernitas maupun pandangan tentang alam, didasarkan pada metafisika. Keduanya "bertemu" dalam usaha memahami lebih luas tentang "alam" itu, tidak sederhana. Karena selama ini, menurut Nasr pemahaman alam itu dibangun atas nalar modernisme. Konsepnya tentu dipengaruhi juga, oleh Frijchof Schuon saat di Amerika dengan konsep "hikmah perenial".

\section{Scientia Sacra}

Paradigma spiritualitas Nasr tampaknya terpengaruh filsafat iluminasi-perennial. Dalam paradigmanya Nasr terdapat konsep tentang scientia sacra. Menurut Nasr, scientia sacra tidak lain adalah pengetahuan suci yang berada dalam jantung setiap wahyu dan ia adalah pusat lingkungan inti yang meliputi dan menentukan "tradisi". Ada dua sumber scientia sacra, yaitu sumber wahyu dan inteleksi atau intuisi intelektual yang menyelimuti iluminasi (cahaya) hati dan pikiran manusia, sehingga dimungkinkan hadirnya pengetahuan yang bersifat langsung,dapat dirasakan dan dialami, atau dalam tradisi Islam disebut dengan al-ilmu alhudluri (ilmu yang hadir) $)^{9}$

Menurut Nasr, scientia sacra pada dasarnya adalah metafisika itu sendiri, jika istilah ini dimengerti secara tepat sebagai puncak sains tentang "Yang Real". Metafisika dalam pengertian bahasa Timur seperti prajna, jnana (dalam tradisi Hindu) dan ma'rifat atau hikmah (dalam tradisi Islam) sebagai sains paripurna tentang "Yang Real" tanpa direduksi ke dalam bentuk cabang pengetahuan lain yang dikenal sebagai filsafat atau padanannya. Dalam pengertian ini hikmah (metafisik) identik dengan scientia sacra.

Scientia sacra memandang semua yang ada pada dasarnya adalah refleksi dari "Yang Real”. Hipostase Ilahi atau Kemutlakan Tertinggi direfleksikan dalam lima kondisi eksistensi. Pertama, dalam ruang sebagai perluasan yang secara teoritik tidak terbatas. Kedua, dalam waktu sebagai durasi yang secara logis tidak berakhir. Ketiga, dalam materi, sebagai eter yang merupakan prinsip baik materi maupun energi yang menandakan ketidakterbatasan substansialitas material. Keempat, dalam bentuk sebagai kemungkinan tak terbatas keanekaragaman, dan kelima, dalam rangka, sebagai ketakterbatasan kuantitas. Scientis sacra melihat aspek-aspek eksistensi kosmik tersebut sebagai refleksi terhadap bidang atau berbagai bidang manifestasi Hipostase Ilahi, Kemutlakan, Ketakterbatasan dan Kebajikan yang mencirikan Yang Real seperti itu. ${ }^{10}$

Di Barat, kajian metafisik ditarik hanya ke wilayah ontologis yang menafikan intuisi intelektual sebagai jalan yang mendalam dalam membayangkan realitas ini. Padahal jauh sebelum itu, seorang filosof muslim, Suhrawardi, telah mengawinkan filsafat dengan pengalaman spiritual. Baginya, pengalaman spiritual yang membuat pengalaman tentang "Wujud" tidak hanya mungkin, tetapi sumber bagi semua spekulasi filosofis berkenaan dengan konsep dan 
realitas Wujud. Scientia sacra memunculkan pengetahuan unitif, yang melihat dunia tidak sebagai ciptaan yang terpisah, tetapi sebagai manifestasi melalui simbol dari setiap pancaran aksistensi pada sumber, yang tidak meniadakan keagungan trensendensi.

Scientia sacra tidak dapat dicapai tanpa inteleksi dan pemanfaatan yang tepat terhadap intelegensi yang terdapat dalam diri manusia. Meskipun intelek memancar di dalam diri manusia, tetapi ia terlalu jauh bergerak dari sifat primordialnya, sehingga tidak mampu menggunakan secara penuh karunia Ilahi ini bagi dirinya sendiri. Ia membutuhkan wahyu, yang dengannya dapat mengaktualisasikan intelek dalam dirinya sendiri. Scentia sacra akan diperoleh ketika tiap manusia adalah seorang Nabi dan ketika intelek berfungsi dalam diri manusia secara natural, maka ia akan melihat segala sesuatu in divinis dan memiliki pengetahuan langsung tentang karakter suci sepanjang masa. Pusat pengetahuan adalah hati. Hati ibarat matahari, sedangkan pikiran ibarat bulan. Bulan memancarkan sinarnya dari pantulan sinar matahari. ${ }^{11}$

Pemikiran modern memandang bahwa ilmu pengetahuan hanyalah realitas empirik, namun Hossein Nasr memandang keseluruhan realitas dari yang eksternal hingga yang paling internal. Menurutnya. berbagai realitas itu dipadukan dalam kalimat tauhid la ilaha illa Allah (tiada tuhan selain Allah) sebagai konsep dasar Islam. ${ }^{12}$ Makna terdalam dari kalimat tersebut adalah tidak ada wujud (realitas) selain wujud Tuhan.

Ia melanjutkan, bahwa kehadiran Ilahi itu dapat disederhanakan dengan membaginya ke dalam lima keberadaan (al-hadharat. alIlahiyah al- Khamsah) untuk menggambarkan hirarki seluruh realitas dalam urutan menurun: (1) kehadiran hakikat ilahiyah, esensi Tuhan (hahut); (2) keberadaan nama dan sifat Tuhan (lahut); (3) kehadiran malaikat (jabarut); (4) keberadaan psikis dan manifestasi halus, disebut juga dunia perantara (malakut); dan (5) keberadaan fana atau dunia fisikal (nasut). ${ }^{13}$

Keberadaan hakikat Ilahiah, adalah wujud yang tidak dapat dikenal dan tidak dapat dijangkau oleh apapun, kecuali Tuhan sendiri. Oleh karena itu, Ia absolut murni. Keberadaan atau dunia hahut, lahut, dan jabarut berada di atas bentuk-bentuk dan manifestasi formal. Sedang dunia malakut mempunyai bentuk meskipun bukan materi dalam pengertian peripatetik biasa. Nama Tuhan tidak dikenal di dunia ini. Ialu ia menyebutkan nama dan sifat-sifat- Nya untuk dikenal. Dan secara emanasi, lahirlah apa yang disebut lahut yang dapat dipersamakan dengan prinsip kreatif atau wujud, yaitu prinsip ontologis dari keseluruhan kosmos. Dengan demikian, ia absolut terhadap seluruh ciptaan. Agar dapat sampai ke dunia, diciptakanlah juga a'yan tsabitah, dimana polapola dasar (archetype).

Malakut adalah mediator antara Tuhan dengan dunia psikis manusia. Malakut adalah keberadaan cahaya atau substansi jiwa yang ada dalam diri manusia, salah satu bagiannya adalah intelek, sebagai cahaya Ilahi yang mampu menghubungkan manusia dengan malakut. Intelek, bagi manusia, merupakan ciri utama yang melampaui realitas lain. Karena intelek itulah, manusia kerap disebut mikrokosmos, sebagai simbol dari makrokosmos. Nasut adalah keberadaan alam fisik. Ia merupakan manifestasi yang paling akhir, ia juga merupakan lambang ketuhanan. Oleh karena itu, intelek disebut juga ayat. Ia bukan hanya bersifat material 
melainkan memiliki makna. Hirarki

keberadaan itulah yang disebut manifestasi Tuhan (tajalliyat). ${ }^{14}$

Doktrin keesaan (tawhid) adalah formulasi metafisikal yang paling mendalam. Ia mempunyai berbagai aspek dan tingkat pengertian: pertama, penekanan pada karakter kesementaraan dan ketaksubstansialan segala sesuatu selain Allah (ma siwa Allah) dan dengan mengikuti urutan ciptaan: yang material adalah yang paling tidak permanen; Kedua, penekanan pada "sesuatu yang lain" sehingga realitas tertinggi menekankan pada kebenaran bahwa Allah sepenuhnya berada di atas seluruh pemikiran dan pengertian awam tentang makna istilah kata "ilah" dalam formulasi di atas.

Dengan mengikuti terminologi Al-Qur'an, Nasr mengemukakan empat kualitas dunia tertinggi: awal, akhir, lahir, dan batin, yang satu sama lain bersifat komplementer. Dua sifat Ilahi pertama, yang Awal dan yang Akhir, bersesuaian dengan kepercayaan waktu di dunia atas asal Ilahi. Tuhan Yang Awal berarti bahwa seluruh realitas berasal dari-Nya, sedangkan Tuhan Yang Akhir berarti semua realitas akan kembali kepadaNya. Dengan kata lain, Ia adalah asal sekaligus tujuan. Dan, dua sifat Ilahi berikutnya, Yang Lahir dan Yang Batin, berhubungan dengan ruang. Tuhan Yang Lahir dan Yang Batin berarti Yang mencakup segalanya ${ }^{15}$.

Metafisika, bagi Nasr, merupakan pengetahuan tentang yang real. Ia menjelaskan asal-usul dan tujuan semua realitas, tentang yang absolut dan relatif. Oleh karena itu, Nasr mengusulkan jika manusia ingin tinggal di dunia lebih lama, prinsip-prinsip metafisis harus dihidupkan kembali. $^{16}$
Dalam memahami alam, yang ditemukan di wisdom-wisdom tradisional yang berada di dalam esensi keagamaan, hikmah perenial, universal knowledge (ilmu sacra, ilmu unity). Scientia Sacra membuka tatanan alam dan sekat-sekat Kimia, Fisika, Matematika, Biologi dan lain-lain. Inilah yang menjadi dasar pembentukan "human spiritual". Jadi manusia adalah pusat dari pengembangan pengetahuan (central of man) disertai dengan kecerdasan ilahi sebagai orientasi perennial. Bahwa yang terjadi di dunia ini adalah menurut hukum alam (cosmic law), serta bersatu dalam kesatuan eksistensi kehidupan (unity of existens)

Nasr berupaya menemukan kembali (rediscovery) tentang alam. Karena wajah alam terlalu positivistic-modernis. Nasr kemudian manawarkan kembali kepada Kalam (Monotheistic of God). Artinya, bagaimana praktik keilmuan itu berbasis pada tauhid. Sebagain contoh, kerusakan lingkungan adalah akibat ketidakseimbangan tangan-tangan manusia, padahal Tuhan memberikan keseimbangan. Nasr adalah serorang tradisionalis, yang sudah barang tentu kehadirannya menjadi angin sejuk Kapitalisme Barat. Inilah yang menjadi pondasi "spiritualitas" dalam pembangunan peradaban, society, politik, sains dan ekonomi.

\section{Kembali ke Tradisi}

Di dalam karya-karyanya, Nasr menunjukkan signifikansi religius dari upaya penegakan ilmu pengetahuan. Ia mengidentifikasi diri sebagai pemikiran tradisional. Jadi, Nasr adalah tradisionalis. Terma tradisi, menurut Nasr, menyiratkan sesuatu yang sakral. ${ }^{17}$ Dengan penggunaan terma tradisi, Nasr tampak menginginkan adanya kejelasan alur dan posisi 
pemikirannya untuk dilihat secara berbeda dari pemikiran "kontra tradisi". Mereka adalah kelompok ilmuwan modern, para pemikir Muslim modernis, dan

fundamentalis. Pembedaan secara kontras ini dilakukan Nasr mengingat masing-masing kelompok itu memiliki karakteristik spesifik.

Dalam wacana ilmu pengetahuan, tradisi dihadapkan pada terma modern. Terma modern bukan dimaksudkan sebagai kontemporer atau mengikuti zaman, melainkan sesuatu yang terpisah dari yang transenden. Dengan demikian, modernisme dipertentangkan dengan al-din. Modernisme mengimplikasikan semua yang semata-mata manusiawi dan semua yang tercerai dan terpisah dari sumber yang Ilahi.

Sekurang-kurangnya ada tiga karakteristik utama yang dapat dijumpai dalam ilmu pengetahuan modern. Pertama, ilmu pengetahuan modern bersifat antropomorfik. Kriteria instrumen-instrumen pengetahuan adalah semata-mata manusia. Sebaliknya, ilmu pengetahuan tradisional benar-benar non-antropomorfik, dalam pengertian bahwa locus dan wadah pengetahuan bukanlah pikiran manusia melainkan, pada akhirnya, kecerdasan Ilahi yang dimiliki tingkat supra manusiawi. Kedua, Prinsip-prinsip yang menjadi ciri ilmu pengetahuan modern tidak ada karena empirisme, rasionalisme, dan rasionalismeempirik tidak dapat bertindak sebagai prinsipprinsip dalam pengertian metafisika. Ketiga, tidak memiliki kepekaan terhadap yang sakral. Sementara itu Islam tidak mengenal konsep profan atau sekuler. Dalam Islam, yang Esa merasuk ke dalam ke dalam dunia multiplisitas dan tidak mengesampingkan domain apapun dari tradisi. ${ }^{18}$

Secara keseluruhan tampaknya, Nasr mengemukakan sebuah kebutuhan untuk menghidupkan kembali kosmologi tradisional di dunia modern. Kosmologi ini memiliki peran penting di dalam setiap usulan yang bertujuan membangkitkan kesadaran akan kesatuan ilmu dan pengetahuan spiritual.

"Tradisi" dalam kaitannya dengan Filsafat Perennial menurut Nasr, secara spesifik memiliki tiga ciri utama: Pertama, kepercayaan kepada sesuatu yang bersifat transendental; Kedua, hakikat kebenarannya dapat dilihat dalam berbagai bentuk agama dan tradisi yang diturunkan pada zaman, masyarakat, dan bahasa yang berbeda. Namun demikian, terdapat satu hakikat di balik tradisi-tradisi otentik itu yang dapat menyatukan pemahaman dimensi transendental; Ketiga, dalam setiap bentuk tradisi terdapat prinsip-prinsip kebenaran dan keindahan. Setiap keindahan dalam tradisi agama-agama merujuk pada hakikat yang sama. Berlandaskan kepada versi tradisi ini, Nasr menganggap bahwa peradaban modern sudah tercemar oleh prinsip-prinsip nonagama, yang pada akhirnya memperlihatkan ciri-ciri kejatuhan manusia (asfala safilin) ${ }^{19}$

Bertitik tolak dari pandangan ini, Nasr menawarkan "Islam Tradisi" sebagai salah satu model "Tradisi” yang perennial, yang menurutnya mampu merespon tantangan zaman, sekaligus mampu menyelesaikan problem kehidupan yang dihadapi manusia modern, khususnya problem pluralitas kehidupan umat beragama. Hal ini dikarenakan Kitab Suci yang dijadikan sebagai landasan pijak dari Islam Tradisi adalah al-Qur'an. Melalui “Tradisi” yang terdapat dalam jantung agama dan hakikat primordial manusia, dengan bantuan intellect sebagai karunia yang berasal dari wahyu Ilahi, 
memungkinkan manusia untuk memperoleh pengetahuan metafisis yang memadai, yakni Tuhan sebagai The Ultimate Reality.

\section{HAKEKAT MANUSIA MENURUT SEYYED HOSSEIN NASR Kejadian Manusia}

Seyyed Hossein Nasr, sebagai salah satu tokoh aliran filsafat ini dengan pendekatan perennialisme dan sufismenya ${ }^{20}$ membahas hakekat manusia dengan memberikan kritik terhadap ideologi dunia modern yang sekarang sedang dihadapi manusia. Baginya, ideologi dunia modern telah menggeser posisi manusia dari pusat eksistensinya, sehingga manusia modern semakin terpinggirkan dari esensi kemanusiaannya dan kehidupan menjadi kehilangan horizon spiritual sehingga menimbulkan berbagai bencana dan krisis lingkungan, sebagaimana dikatakannya:

... Kehidupan di dunia ini tampaknya masih tidak memiliki horizon spiritual. Hal ini bukan karena horizon spiritual itu tidak ada, tetapi karena yang menyaksikan panorama kehidupan kontemporer ini seringkali adalah manusia yang hidup di pinggiran lingkaran eksistensi, sehingga ia hanya dapat menyaksikan segala sesuatu dari sudut pandangannya sendiri. Ia senantiasa tidak peduli dengan jari-jari lingkaran eksistensi dan sama sekali lupa dengan sumbu maupun pusat lingkaran eksistensi yang dapat dicapainya melalui jari-jari tersebut. ${ }^{21}$

Sesuai dengan ide Tradisionalisme Islam yang dibawanya, Nasr selalu mengaitkan setiap pembahasannya dengan teks-teks Alquran dan Hadits. Manusia menurut Nasr didefinisikan dalam hubungannya dengan Tuhan, tanggung jawab dan hak-hak manusia dirumuskan dari hubungan tersebut. Form atau bentuk manusia merupakan refleksi dari Nama-Nama dan Sifat-Sifat Tuhan. Refleksi Sifat Tuhan dalam diri manusia ini sebagaimana cermin yang merefleksikan cahaya matahari. $^{22}$

Pengaruh sufisme Ibnu 'Arabi tampak jelas dalam pemikiran Nasr, ia menegaskan bahwa menurut Islam, tujuan kemunculan manusia di dunia adalah untuk memperoleh pengetahuan total tentang benda, untuk menjadi Manusia Universal (al-insan al-kamil), yaitu cermin yang memantulkan semua Nama dan Sifat Allah. Bagi Tuhan, maksud dan tujuan penciptaan manusia adalah untuk "mengetahui" diri-Nya melalui instrumen pengetahuan-Nya yang sempurna, yakni Manusia Universal. ${ }^{23}$

Dalam membahas kejadian manusia, Nasr membandingkan konsep Islam dan agamaagama lain terutama Kristen dan Yahudi. Nasr menyimpulkan adanya kesamaan konsep dalam setiap agama dan tradisi tentang kejadian manusia terutama dalam hal adanya aspek Ketuhanan dalam diri manusia, sesuatu yang merupakan pancaran dunia spiritual. ${ }^{24}$

Fase pertama penciptaan manusia menurut Nasr adalah ketika manusia diturunkan dari ruh yang merupakan milik Allah $^{25}$, dengan demikian terdapat dimensi Ketuhanan dalam diri manusia. Di sini Nasr berusaha menegaskan bahwa ruh manusia bukanlah ciptaan Allah, karena dalam berbagai ayat tentang kejadian manusia, selalu dijelaskan bahwa Allah meniupkan ruh-Nya ke dalam jasad manusia, artinya, menurut Nasr, jasad manusia diciptakan dan kemudian Allah meniupkan ruh-Nya ke dalam jasad tersebut sebagai karunia yang menunjukkan kedudukan tertentu yang 
dimiliki manusia.

Akan tetapi, Nasr menegaskan bahwa konsep ini tidak mengubah Tuhan menjadi manusia atau sebaliknya, juga tidak ada kemungkinan inkarnasi dimensi ke-Tuhanan dan kemanusiaan dalam diri manusia, melainkan menggambarkan manusia sebagai makhluk theomorfis yang memiliki sesuatu yang agung dalam dirinya. Allah dengan sengaja menciptakan manusia sebagai cermin yang memantulkan Nama dan Sifat-Nya, tegasnya ada sesuatu yang suci dalam diri manusia. ${ }^{26}$

Penyatuan puncak dalam perspektif Nasr lebih berorientasi pada pengalaman religius manusia yang membuatnya menjadi manusia seutuhnya sebagaimana penjelasan Nasr:

Manusia, sebagai wakil Tuhan di bumi (khalifah) dan panggung di mana nama-nama dan Sifat-Sifat Tuhan dipertunjukkan, bisa mencapai kebahagiaan hanya dengan tetap memegang teguh kodratnya ini atau dengan menjadi dirinya secara sungguh-sungguh. Dan ini sebagai akibatnya berarti ia harus menjadi utuh. Tuhan adalah satu dan demikian manusia harus menjadi menyeluruh di dalam rangka untuk menjadi satu. Tercerai-berai dan terpisah-pisah, tenggelam di dalam permainan gambar dan konsekonsep mental yang tak habis-habisnya, atau mengalami ketegangan dan tekanan kejiwaan, adalah berarti terpisah jauh dari keadaan menyeluruh yang dituntut hati nurani kita. Banyak orang dewasa ini lebih menyukai dirinya melampaui batas dengan segala pengorbanan, malahan lebih memiliki demikian dan memasuki neraka daripada menjadi wajar dan berjalan menuju surga; sekalipun demikian, dibanding sifat melampaui batas, sifat wajar lebih dekat kepada ketakberdosaan dan kemurnian yang merupakan keadaan surgawi yang indah, seperti Nabi Isa mengatakan bahwa kita harus menjadi seperti kanak-kanak supaya bisa masuk surga. ${ }^{27}$

Fase kedua dalam penciptaan manusia adalah ketika ia diciptakan sebagai logos yang menjadi prototipe semua manusia dan segala ciptaan, dalam Islam logos, tegas Nasr, adalah Nabi Muhammad. ${ }^{28}$ Nabi Muhammad, sebagai pembawa Islam, merupakan Nabi terakhir yang diutus Allah ke dunia, meskipun seluruh nabi dalam Islam memiliki aspek logos tersebut, akan tetapi menurut Nasr, Hakikat Muhammad yang menjadi ciptaan Allah yang pertama - konsep yang sama dengan konsep Nur Muhammad dalam tasawuf - sehingga secara batin beliau datang sebelum nabi yang lain pada awal siklus kenabian dan sebagai perwujudan penuh dari sifat kemanusiaan yang sempurna, Muhammad adalah Manusia Universal (alinsan al-kamil), dan aspek batinnya merupakan logos. ${ }^{29}$

...Seperti pohon yang tumbuh dari sebuah bibit yang kemudian berkembang dengan subur dan akhirnya berbuah yang mengandung bibit yang serupa, begitu pulalah siklus kenabian yang dimuali dengan Hakikat Muhammad, dan diakhiri dengan manifestasinya sebagai manusia. Secara batin ia adalah awal silus kenabian dan secara lahir ia adalah akhir siklus kenabian yang telah ia satukan dan integrasikan dalam dirinya. Pada lahirnya ia manusia biasa, dan secara batin ia Manusia Universal yang menjadi norma segala kesempurnaan... ${ }^{30}$

Keberadaan Nabi Muhammad sebagai logos ini terutama dari fungsi kenabiannya sebagai pembawa wahyu Ilahi. Peranannya sebagai khatim al-anbiya' memulai sebuah 
siklus kesucian yang diistilahkan Nasr dengan "kesucian Muhammad" yang selalu ada dan menjadi kekuatan spiritual dalam Islam, sehingga tidak lagi diperlukan adanya agama baru sesudah Islam, sebab wahyu yang dibawa Nabi Muhammad dengan sendirinya mengandung segala hal yang diperlukan untuk memenuhi kebutuhan religius dan spiritual setiap muslim.

Fase ketiga dalam kejadian manusia adalah manusia dalam level kosmik, yaitu Nabi Adam sebagai penghuni surga sebelum kejatuhan yang dialaminya sehingga diturunkan ke bumi dan selanjutnya menjadi manusia terestrial. ${ }^{31}$

Fase keempat kejadian manusia adalah setelah diturunkan ke bumi, di mana manusia tidak lagi berada dalam level kosmik, tetapi telah berpindah ke dunia fisik. Pada fase ini manusia melengkapi penciptaan alam sebagai wakil (khalifah) Tuhan di bumi yang diberi kemampuan untuk mengetahui segala sesuatu, menundukkan bumi, kekuasaan untuk melakukan kebaikan tetapi di sisilain juga dapat menimbulkan kerusakan dan kehancuran bumi. ${ }^{32}$

\section{Manusia Suci}

Konsep scientia sacra, nampaknya membuat Nasr memiliki konsep manusia suci. Manusia Suci dalam pengertian Nasr adalah manusia tradisional yang hidup di dalam dunia yang mempunyai "Asal maupun Pusat". Dia hidup dalam kesadaran penuh, sejak Asal yang mengandung kesempurnaannya sendiri dan berusaha untuk menyamai, memiliki kembali, dan mentransmisikan kesucian awal dan keutuhannya. Dia juga hidup dalam lingkaran pusat yang senantiasa sadar dan berupaya mencapai, berpikir, dan bertindak dalam hidupnya. Dalam pengertian lain, Manusia Suci adalah Khalifah Allah di bumi yang bertanggung jawab kepada-Nya atas segala tindakan, penjaga dan pelindung bumi yang senantiasa percaya diri sebagai figur terestrial pusat yang diciptakan dalam "bentuk Tuhan". ${ }^{33}$

Perspektif Nasr bahwa Manusia Suci adalah "figur terestrial pusat yang diciptakan dalam "bentuk Tuhan"” di atas menunjukkan penekanan terhadap dimensi Ketuhanan dalam diri manusia yang menurut Nasr tidak dapat diingkari.

Dari perspektif scintie sascra tubuh manusia itu sendiri adalah bukti bahwa manusia dikembangkan dari asal surgawi, dia dilahirkan untuk tujuan yang melampaui batas-batas kebinatangannya. Definisi manusia sebagai wujud sentral yang direfleksikan bukan hanya dalam pikiran, pembicaraan, dan kemampuan internalnya yang lain, tetapi juga dalam tubuhnya yang berdiri pada pusat lingkaran eksistensi terestrial, memiliki keindahan dan signifikansi yang berasal dari alam spiritual murni. Tubuh setiap laki-laki dan perempuan melahirkan takdir kemanusiaan, sebagai suatu ciptaan yang dilahirkan untuk immortalitas, ciptaan yang kesempurnaannya menempa peningkatan dimensi eksistensi vertikal, mencapai pusat dimensi horizontal. Mereka yang mencapai titik silang, adalah manusia yang mendaki sumbu vertikalnya, yang merupakan jalan untuk mentransendensikan dirinya sendiri menuju manusia seutuhnya, menjadi manusia adalah melampaui dirinya sendiri. Sebagaimana Saint Agustinus menyatakan, untuk tetap menjadi manusia, manusia harus enjadi superhuman. Manusia juga memiliki berbagai kemampuan internal, suatu memori yang 
jauh lebih prestisius daripada yang dapat digambarkan produk pendidikan modern. Suatu yang memainkan peranan paling positif dalam aktivitas intelektual dan artistik dari manusia tradisional. ${ }^{34}$

Menurutnya manusia suci adalah refleksi dari Pusat periferi dan gaung dari Asal dalam siklus dan waktu dan generasi sejarah yang terakhir. Dia adalah wakil Tuhan (khalifatullah) di bumi bertanggung jawab kepada Tuhan atas tindakan-tindakannya, penjaga dan pelindung bumi, senatiasa percaya diri, sebagai figur terestial pusat yang diciptakan dalam "bentuk Tuhan," suatu kehidupan teomorfik di dunia ini, tetapi dicipta untuk keabadian. ${ }^{35}$

\section{Pendidikan Spiritualitas Seyyed Hossein Nasr}

Berbicara masalah pendidikan, Nasr membicarakan tidak secara terperinci, dalam bukunya yang berjudul "Traditional Islam in the Modern World", yang diterjemahkan oleh Luqman Hakim, secara keseluruhan dapat dipaparkan dalam aspek-aspek berikut. Menurut Nasr bahwa prinsip-prinsip yang mendasari pendidikan Islam pada gilarannya mustahil untuk dipahami tanpa apresiasi atas pandangan para filosof berkenaan dengan aspek pendidikan mulai dari tujuan hingga kandungannya dan dari kurikulum hingga metode-metodenya. ${ }^{36}$

Tugas pendidikan, lanjut Nasr, untuk mempersiapkan manusia dalam mencapai kebahagiaan hidup di dunia, sedangkan tujuan ultimatnya adalah tercapainya kebahagiaan hidup yang permanent di alam baka (al akhirah) ${ }^{37}$ Nasr menambahkan sistem pendidikan Islam klasik (tradisional), yang selama berabad-abad menghasilkan filosoffilosof, ilmuwan-ilmuwan, yuris-yuris, teolog- teolog, sastrawan-sastrawan dan pakar-pakar di berbagai bidang keilmuan, harus dijadikan contoh model bagi pengembangan pendidikan sekarang, agar pendidikan tidak kehilangan daya mobilitasnya, baik mobilitas vertikal maupun horizontal dalam menghadapi dunia modern. Institusi-institusi pendidikan Islam klasik, adalah paling signifikan untuk tercapainya perjumpaan Islam tradisional dan modernisme.

Dalam persoalan ini, Nasr mengklasifikasikan sains-sains dalam Islam. Pertama, sains keagamaan (sains aqli), yang meliputi Hukum Ilahi (Syari'ah), prinsipprinsipnya (Ushul), Jurispudensi (fiqh), tafsir, hadits dan teologi. Kedua, sains-sains intelektual (sains aqli) yang meliputi, misalnya matematika, sains-sains kealaman, filsafat, logika dan semacamnya. ${ }^{38}$ Menurut Nasr, pembagian sains-sains ini terefleksi dalam sekolah-sekolah Islam tradisional, yang sebagian besar mengajarkan beberapa sains naqli dan aqli secara integral. Pengajaran sains aqli tidak terlepas dari keterikatannya dengan agama. Bahkan puncak-puncak sains-sains aqli berdiri filsafat atau kebijaksanaan Ilahi (alHikmah al-llahiyyah).

Pendidikan spiritualitas Nasr dapat dilihat dari hubungan manusia dengan Tuhan menurut Nasr. Tergambar dengan jelas dalam ayat 56 Surah adz-Dzariyat. Perintah penyembahan dalam ayat tersebut, menurut Nasr menegaskan bahwa manusia secara mutlak merupakan hamba Tuhan. Ini juga menunjukkan bahwa salah satu tujuan penciptaan manusia dalam Islam adalah agar manusia beribadah dan melayani Tuhan. ${ }^{39}$ Konsekuensi dari penghambaan manusia ini adalah perlunya kehidupan beragama.

Hubungan manusia dengan Tuhan berada pada titik pusat setiap agama, yang 
merupakan jalan bagi manusia untuk mendekatkan dirinya kepada Tuhan. Agama juga merupakan motivasi dalam melakukan suatu aktivitas, karena perbuatan yang dilakukan dengan latar belakang keyakinan agama dinilai mempunyai unsur kesucian serta ketaatan. Kemuliaan manusia bukan berasal dari dirinya sendiri, melainkan dari posisinya sebagai hamba yang mampu melaksanakan apa Kehendak Majikan Tertinggi alam semesta. ${ }^{40}$

Ajaran Islam, menurur Nasr, adalah ajaran yang didasarkan pada ajaran menyeluruh tentang watak Ilahiah, yakni Yang Maha Esa tanpa sekutu apa pun. Syahadat yang menjadi dasar keislaman seseorang, dikatakannya, berisi ajaran yang utuh tentang Allah karena menghalau relativitas, kemenduaan dan kemungkinan lain dari Keilahian dan berisi pengetahuan tentang Tuhan berdasarkan Keesaan-Nya. Allah adalah Esa, Absolut, Maha Tak Terbatas dan Sumber seluruh realitas. ${ }^{41}$

Ringkasnya, Islam didasarkan pada hubungan yang universal antara Tuhan dengan manusia; Tuhan dalam KemutlakanNya, dan manusia dalam bentuk theomorfisnya. Hubungan ini didasarkan pada akal, kehendak dan kemampuan berbicara, serta pada keseimbangan dan kepastian. Islam menjaga keseimbangan dalam kehidupan dengan mengatur kebutuhan alamiah manusia melalui syari'at. Dan dengan keseimbangan sebagai dasar, Islam memungkinkan manusia untuk membangun dunia spiritual yang didasarkan pada renungan dan kepastian tentang Keesaan Tuhan. ${ }^{42}$

Dua karakter utama manusia adalah pengabdian atau penghambaan dan kekhalifahan. Yang pertama berlaku pasif terhadap Tuhan dengan menyerahkan diri kepada Kehendak-Nya, dan yang kedua, berlaku aktif dalam posisi sebagai wakil Tuhan dan melaksanakan Kehendak-Nya di dunia. Selain itu, Adam telah diajari tentang semua nama. Artinya, Tuhan telah menempatkan dalam diri manusia suatu kemampuan berpikir yang sangat vital, yang dengan kemampuan ini manusia dapat mengetahui segala sesuatu. Hal ini juga berarti bahwa manusia sendiri adalah bayangan Tuhan atau manifestasi fisik dari semua Nama-Nama Tuhan. ${ }^{43}$

Jadi, pendidikan spiritualitas Nasr adalah tanggung jawab manusia kepada Tuhan. Tanggung jawab spiritual muncul akibat dari jawaban (komunikasi) manusia awal mula sekali terhadap Tuhan. Al-Quran sebagai kitab yang tidak ada keraguan di dalamnya membicarakan perjanjian pra-eternal (azali) manusia dengan Tuhan, ketika dia menjawab panggilan Tuhan, "Bukankah Aku Tuhanmu?" dengan afirmasi, "Ya." ${ }^{44}$ Sebagaimana firman Allah swt;

"Dan (ingatlah), ketika Tuhanmu mengeluarkan keturunan anak-anak Adam dari sulbi mereka dan Allah mengambil kesaksian terhadap jiwa mereka (seraya berfirman): "Bukankah Aku Ini Tuhanmu?" mereka menjawab: "Betul (Engkau Tuhan kami), kami menjadi saksi". (Kami lakukan yang demikian itu) agar di hari kiamat kamu tidak mengatakan: "Sesungguhnya kami (Bani Adam) adalah orang-orang yang lengah terhadap ini (keesaan Tuhan)" (Q.S. alA'raaf[7]: 172).

Menurut Nasr, kalimat "Bukankah Aku Tuhanmu?" (alastu bi rabbikum), menyimbolisasikan hubungan antara Tuhan dan manusia sebelum penciptaan. Dan dalam 
pengakuan ini, tersandar semua tanggung jawab manusia karena manusia dengan menjawab "Ya", berarti manusia menerima kepercayaan Tuhan (amanah), yang harus dilaksanakan oleh manusia di dunia ini. ${ }^{45} \mathrm{Di}$ dalam amanah terletak pengakuan akan keesaan Tuhan dan tindakan-tindakan ibadah dan pelayanan. Kata untuk arti "hamba Tuhan" itu sendiri ('abd) terkait dengan kata yang berarti penyembahan dan pelayanan ('ibadah). Oleh karena itu Nasr membagi tanggungjawab manusia sebagi wujud spiritualitas sebagai berikut:

Pertama, spiritualitas terhadap tuhan "act of worship and service and obedience to His Law"46(tindakan-tindakan ibadah dan pelayanan serta kepatuhan kepada HukumNya). Oleh karenanya manusia disebut sebagai hamba Allah. Menurut Nasr, manusia sebagai hamba Allah harus patuh kepada kehendak-Nya. Manusia harus pasif secara total vis-à-vis kepada kehendak Allah, menerima dari-Nya petunjuk untuk hidupnya dan perintah bagaimana melaksanakan kehendak-Nya menurut hukum alam. ${ }^{47}$

Kedua, Spiritualitas manusia terhadap dirinya "responsibilty our soul and mind and then try to save our soul and to be good"48 (tanggung jawab kepada jiwa dan akal kita dan berusaha untuk menyelamatkan dan membuat jiwa ini menjadi lebih baik).

Karena kehidupan manusia adalah sakral dan tidak diciptakan oleh manusia, maka manusia bertanggung jawab untuk mengusahakan agar jiwa dan tubuh manusia terjaga kesehatannya dan untuk tidak membahayakan diri manusia secara fisik maupun spiritual. Manusia juga mempunyai tanggung jawab terhadap akal dengan cara mencari pengetahuan dan kebenaran sebanyak-banyaknya. ${ }^{49}$
Ketiga, spiritualitas terhadap masyarakat, "Starting with our family, this set of responsibility all the way from working honestly to support ourselves and our families, to performing acts of charity, to respecting others and strengthening community bonds, to supporting and sustaining all that is positively creative in human society". ${ }^{50}$ Spiritualitas ini dimulai dengan keluarga, yang didalamnya terdiri dari segala macam perbuatan mulai dari bekerja dengan jujur untuk membiayai dan keluarga, melakukan perbuatan kedermawanan, menghargai orang lain, memperkuat ikatan-ikatan kemasyarakatan, dan mendukung dan memelihara semua hasil ciptaan yang positif dalam masyarakat.

Keempat, spiritualitas manusia terhadap lingkungan "responsibility toward animals and plants and even inanimate parts of nature such as water, air, and soil" (tanggung jawab terhadap hewan dan tanaman dan bahkan bagianbagian alam yang tidak hidup seperti air, udara, dan tanah) $)^{51}$ dengan memanfaatkan sebaik-baiknya. Kumpulan tanggung jawab yang terakhir ini berkenaan dengan hal yang disebut oleh penulis Barat modern sekarang sebagai etika lingkungan. ${ }^{52}$

\section{KESIMPULAN}

Metafisika, bagi Nasr, merupakan pengetahuan tentang "Yang Real". Ia menjelaskan asal-usul dan tujuan semua realitas, tentang yang absolut dan relatif. Oleh karena itu, Nasr mengusulkan jika manusia ingin tinggal di dunia lebih lama, prinsip-prinsip metafisis harus dihidupkan kembali. Dalam memahami alam, Nasr menemukan dalam wisdom-wisdom tradisional yang berada di dalam esensi keagamaan, hikmah perenial, universal knowledge (ilmu sacra, ilmu unity). Scientia Sacra membuka 
tatanan alam dan sekat-sekat Kimia, Fisika, Matematika, Biologi dan lain-lain. Inilah yang menjadi dasar pembentukan "human spiritual". Jadi manusia adalah pusat dari pengembangan pengetahuan (central of man) disertai dengan kecerdasan ilahi sebagai orientasi perennial. Bahwa yang terjadi di dunia ini adalah menurut hukum alam (cosmic low), serta bersatu dalam kesatuan eksistensi kehidupan (unity of existens)

Nasr berupaya menemukan kembali (rediscovery) tentang alam. Karena wajah alam terlalu positivistic-modernis. Nasr kemudian manawarkan kembali kepada Kalam (Monotheistic of God). Artinya, bagaimana praktik keilmuan itu berbasis pada tauhid. Sebagain contoh, kerusakan lingkungan adalah akibat ketidakseimbangan tangan-tangan manusia, padahal Tuhan memberikan keseimbangan. Nasr adalah serorang tradisionalis, yang sudah barang tentu kehadirannya menjadi angin sejuk Kapitalisme Barat. Inilah yang menjadi pondasi "spiritualitas" dalam peradaban, society, politik, sains dan ekonomi dibangun. "Tradisi", yang disebut Nasr sebagai scientia sacra, yakni pengetahuan suci yang terkandung di dalamnya nilai-nilai universal, unitas kebenaran dan pluralitas pemahaman, serta bersifat perennial.

\section{CATATAN AKHIR}

1 Ali Maksum, Tasawuf Sebagai Pembebasan Manusia Modern: Telaah Signifikansi Konsep "Tradisionalisme Islam" Seyyed Hossein Nasr, (Yogyakarta: Pustaka Pelajar, 2003), Cet. I. h. 35-

2 Zainul Hasan, Islam Tradisional; Kajian atas Pemikiran Nasr, (Pamekasan: Journal Studi Keislaman, Vol,V, No.l. STAIN Pamekasan, 2004), h. 342.

3 Komaruddin Hidayat, "Upaya Pembebasan Manusia Sufistik Terhadap Manusia Modern Menurut Seyyed Hossein Nasr", Insan Kamil: Konsep Manusia Menurut Islam, Peny. M. Dawam Rahardjo, (Jakarta: Pustaka Grafiti Pers, 1987), Cet. 2. h. 183.

4 Azyumardi Azra, Historiografi Islam Kontemporer, (Jakarta: Gramedia, 2002), Cet. 1. h.193-194.
5 A. Khudori Soleh, Wacana Baru Filsafat Islam,

(Yogyakarta: Pustaka Pelajar, 2004), Cet. I.

h. 317

6 A. Khudori Soleh, Wacana Baru Filsafat Islam, h. 317318.

7 A. Khudori Soleh, Wacana Baru Filsafat Islam, h. 318319.

8 Ali Maksum, Tasawuf Sebagai Pembebasan, h. 56-64.

9 Sayyed Hossen Nasr, Pengetahuan dan Kesucian, terj. Suharsono (Yogyakarta: Pustaka Pelajar, 1997) h. 152

10 Nasr, Pengetahuan dan Kesucian, h.158.

11 Nasr, Pengetahuan dan Kesucian, hal. 171-172.

12 Seyyed Hossein Nasr, Man and Nature: The Spiritual Crisis of Modern Man. London: Mandala Books, h. 18.

13 Seyyed Hossein Nasr, Sains dan Peradaban dalam Islam (Bandung: Pustaka, 1986), h. 74. Lihat pula Knowledge and the Sacred, 1981. h. 199

14 Seyyed Hossein Nasr, Three Muslim Sages (New York: Caravan Books, 1976), h. 111-112.

15 Seyyed Hossein Nasr, Three Muslim Sages, h. 75

16 Seyyed Hossein Nasr, Man and Nature, h. 81.

17 Tentang makna tradisi, lihat Seyyed Hossein Nasr, Islam Tradisi di Tengah Kancah Dunia Modern, (Bandung: Pustaka, 1994), h. 1-13.

18 Seyyed Hossein Nasr, Islam Tradisi, h. 100.

19 Syed Hossein Nasr, In Search of The Sacred, A Conversation with Seyyed Hossein Nasr on His Life and Thought (England: Praeger, 2010), h. 241.

20 Lihat, Nur Said, "Kritik Tradisionalisme Islam Terhadap Krisis Dunia Modern (Studi atas Pemikiran Seyyed Hossein Nasr)," An-Nur, Vol. I, No. 2, Februari 2005, h. 280 dan 282

21 Seyyed Hossein Nasr, Islam dan Nestapa Manusia Modern, terj. Anas Muhyiddin (Bandung: Pustaka, 1983), h. 4. Judul aslinya: Islam and The Plight of Modern Man.

22 Seyyed Hossein Nasr, The Heart of Islam: Pesan-Pesan Universal Islam Untuk Kemanusiaan, terj. Nurasiah Fakih Sutan Harahap (Bandung: Mizan, 2003), h. 336. Judul aslinya: The Heart of Islam: Enduring Values for Humanity.

23 Seyyed Hossein Nasr, Antara Tuhan, Manusia dan Alam, terj. Ali Noer Zaman (Yogyakarta: IRCiSoD, 2003), h. 115-116. Judul aslinya: The Encounter Man and Nature

24 Seyyed Hossein Nasr, Inteligensi dan Spiritualitas Agama-Agama, terj. Suharsono, et. al. (Depok: Inisiasi Press, 2004), h. 177. The Knowledge and The Sacred.

25 Seyyed Hossein Nasr, Menjelajah Dunia Modern: Bimbingan Untuk Kaum Muda Muslim, terj. Hasli Tarekat (Bandung: Mizan, 1994), h. 41. Judul aslinya: A Young Muslim's Guide to the Modern World.

26 Seyyed Hossein Nasr, terj. Abdurrahman Wahid dan Hashim Wahid dengan judul Islam dalam Cita dan Fakta, (Jakarta: LEPPENAS, 1981), h. 4 dan 177. Judul aslinya: Ideals and Realities of Islam

27 Seyyed Hossein Nasr, Tasawuf Dulu dan Sekarang, terj. 
Abdul Hadi WM (Jakarta: Pustaka Firdaus, 2000), h. 3738. Judul aslinya: Living Sufism.

28 Dalam setiap agama, penyebar atau pendirinya selalu diidentifikasikan sebagai logos, dalam Kristen, logos diidentifikasi sebagai Kristus seperti dijelaskan dalam Injil Yohannes. Lihat, Ibid, h. 57,

29 Seyyed Hossein Nasr, Ideals..., h. 57.

30 Seyyed Hossein Nasr, Ideals..., 59

31 Seyyed Hossein Nasr, The Encounter..., h. 115.

32 Seyyed Hossein Nasr, The Heart of Islam..., h. 18.

33 Seyyed Hossein Nasr, The Knowledge..., h. 167.

34 Scientia Sacra atau Pengetahuan Suci adalah pengetahuan yang menurut Nasr merupakan inti dari setiap wahyu yang bersifat langsung, dapat dirasakan dan dialami, ruhaniyah. Dalam istilah lain Nasr menyebutnya dengan al-ilm al-hudhuri. Isi pokok pengetahuan ini adalah tentang Ketuhanan. Dalam pengertian tradisional, ma'rifah atau metafisika dapat diidentikkan dengan Scientia Sacra. Lihat, Seyyed Hossein Nasr, The Knowledge..., h. 135-137.

35 Seyyed Hossein Nasr, Inteligensi dan Spiritualitas Agama-agama, terj. Suharsono, dkk. (Jakarta: Inisiasi Press, 2004), Cet. 1., h. 167.

36 Seyyed Hossein Nasr, Islam Tradisi di Kancah Dunia Modern, terj. Lukman Hakim,(Bandung: Pustaka, 1994), Cet. 1, h. 150.

37 Seyyed Hossein Nasr, Islam Tradisi, h. 150.

38 Seyyed Hossein Nasr, Islam Tradisi, h. 128.

39 Seyyed Hossein Nasr, The Heart of Islam..., h. 339.

40 Seyyed Hossein Nasr, The Heart of Islam..., h. 339.

41 Seyyed Hossein Nasr, A Young Muslim's..., h. 30-40

42 Seyyed Hossein Nasr, Ideals...., h. 20.

43 Seyyed Hossein Nasr, The Heart of Islam...., h. 16.

44 Seyyed Hossein Nasr, The Heart of Islam, terj. Nurasiah Fakih Sutan Harap, (Bandung: Mizan, 2003), Cet. 1, h. 338

45 Seyyed Hossein Nasr, h. 177.

46 Seyyed Hossein Nasr, The Heart of Islam, h.. 278.

47 Seyyed Hossein Nasr, A Young Muslim's Guide to The Modern World, terj. Hasti Tarekat, (Bandung: Mizan, 1993), Cet. 1, h. 40.

48 Seyyed Hossein Nasr, The Heart of Islam, h. 279.

49 Seyyed Hossein Nasr, The Heart of Islam, h. 340.

50 Seyyed Hossein Nasr, The Heart of Islam, h.. 279.

51 Seyyed Hossein Nasr, The Heart of Islam, h. 279.

52 Seyyed Hossein Nasr, The Heart of Islam, h. 342.

\section{DAFTAR PUSTAKA}

A.Khudori Soleh. 2004. Wacana Baru Filsafat Islam. Yogyakarta: Pustaka Pelajar.

Ali Maksum. 2003. Tasawuf Sebagai Pembebasan Manusia Modern: Telaah Signifikansi Konsep "Tradisionalisme Islam" Seyyed Hossein Nasr. Yogyakarta: Pustaka Pelajar. Azyumardi Azra. 2002. Historiografi Islam Kontemporer. Jakarata: Gramedia.
Husna Amin. 2013. Ringkasan Disertasi. "Tradisi Menurut Filsafat Perennial Seyyed Hossein Nasr dan Relevansinya bagi Pluralitas Kehidupan umat Beragama di Indonesia". Program Doktor Program Studi Ilmu Filsafat Fakultas Filsafat Universitas Gadjah Mada. Yogyakarta

Komaruddin Hidayat. 1987. "Upaya Pembebasan Manusia Sufistik Terhadap Manusia Modern Menurut Seyyed Hossein Nasr", Insan Kamil: Konsep Manusia Menurut Islam, Peny. M. Dawam Rahardjo. Jakarta: Pustaka Grafiti Pers.

Nasr, Seyyed Hossein. 1994. A Young Muslim's Guide to the Modern World, terj. Hasli Tarekat dengan judul Menjelajah Dunia Modern: Bimbingan Untuk Kaum Muda Muslim, Bandung: Mizan. .1981.Ideals and Realities of Islam, terj. Abdurrahman Wahid dan Hashim Wahid dengan judul Islam dalam Cita dan Fakta, Jakarta: LEPPENAS, 1983. Islam and The Plight of Modern Man, terj.

Anas Muhyiddin dengan judul Islam dan Nestapa Manusia Modern. Bandung: Pustaka. 2000. Living Sufism, terj. Abdul Hadi WM dengan judul Tasawuf Dulu dan Sekarang. Jakarta: Pustaka Firdaus.

2003. The Encounter Man and Nature, terj. Ali Noer Zaman dengan judul Antara Tuhan, Manusia dan Alam. Yogyakarta: IRCiSoD. 2003. The Heart Of Islam: Enduring Values for Humanity, terj. Nurasiah Fakih Sutan Harahap dengan judul The Heart Of Islam: Pesan- Pesan Universal Islam Untuk Kemanusiaan. Bandung: Mizan.

. 2004. The Knowledge and The Sacred, terj. Suharsono, et. al. Dengan judul Inteligensi dan Spiritualitas Agama-Agama, Depok: Inisiasi Press.

Rafi'ah Gazali. 2013. Laporan Penelitian. "Manusia Menurut Seyyed Hossein Nasr". Kementerian Pendidikan dan Kebudayaan Universitas Lambung Mangkurat Fakultas Keguruan dan Ilmu Pendidikan Program S1 Pendidikan Guru Sekolah Dasar Banjarmasin

Zainul Hasan. 2004. Islam Tradisional; Kajian atas Pemikiran Nasr. Journal Studi Keislaman, Vol,V, No.l. STAIN Pamekasan. 